\title{
FERMENTAÇÃO ALCÓOLICA DO HIDROLISADO DE BAGAÇO DE CANA-DE-AÇÚCAR CONCENTRADO COM MELAÇO: CINÉTICA VIA REDES NEURAIS ARTIFICIAIS
}

\author{
L. A. P. SOARES, R. R. ANDRADE e T. D. MARTINS \\ Universidade Federal de São Paulo, Departamento de Ciências Exatas e da Terra \\ E-mail para contato: lucas_adriel1@ @otmail.com; tdmartins@unifesp.br
}

\begin{abstract}
RESUMO - Visando melhorar o desempenho do processo de fermentação alcóolica, é importante que se tenha um modelo cinético que seja preciso e se possível, simples. As Redes Neurais Artificiais (RNAs) tem mostrado grande capacidade estrutural para auxiliarem na busca desse modelo. Neste trabalho foram utilizadas RNAs para se modelar os dados da fermentação alcóolica em diferentes temperaturas, na faixa de $30{ }^{\circ} \mathrm{C}$ a $38{ }^{\circ} \mathrm{C}$, utilizando como meio de cultivo, hidrolisado de bagaço de cana-de-açúcar concentrado com melaço. A temperatura e os valores da concentração de substrato, células e etanol no tempo t e t-1 foram utilizados como variável de entrada, sendo as concentrações de substrato, células e etanol no tempo $t+1$ as de saída. Foram testadas redes com 3 a 10 neurônios na camada intermediária, a que havia 10 neurônios foi a que apresentou as melhores simulações. Os resultados obtidos mostraram que uma única RNA é capaz modelar satisfatoriamente o processo.
\end{abstract}

\section{INTRODUÇÃO}

São diversos os estudos relacionados à utilização de biomassa para a produção de energia, por conta da redução de reservas de combustíveis fósseis e do aquecimento global. A fermentação alcóolica do hidrolisado do bagaço de cana-de-açúcar é um desses processos que está em alta, já que utiliza uma fonte de energia renovável. A falta de informação relacionada à cinética de crescimento da Saccharomyces cerevisiae em meios de cultivo contendo ácido acético, furfural e hidroximetilfurfural, presentes no hidrolisado de bagaço de cana-de-açúcar faz com que exista a necessidade de técnicas para simplificar a modelagem e o controle desse processo (Andrade, 2012).

Nesse momento é que as Redes Neurais Artificiais (RNAs) se destacam. Elas são uma alternativa à modelagem convencional, pois oferecem flexibilidade para se adaptar a sistemas completamente diferentes e podem generalizar o modelo para mais de um experimento (Fonseca et al., 2000). Elas são formadas por neurônios artificiais que são baseados no funcionamento do neurônio biológico. Sua estrutura é basicamente formada por uma camada de entrada, uma camada de saída e camadas ocultas, conforme mostra a Figura 1.

Cada camada é formada por neurônios, que por sua vez, possuem pesos sinápticos. O número de neurônios é ajustável em cada camada e a determinação dos pesos constitui a obtenção do modelo neural. Seu funcionamento ocorre por meio de estímulos gerados da 
camada anterior que são associados a pesos através da função soma. Por meio de funções lineares ou não-lineares a saída do elemento de processamento é determinada (Braga et al., 2000).

Figura 1 - Estrutura de um RNA. FONTE: Klassen, 2008

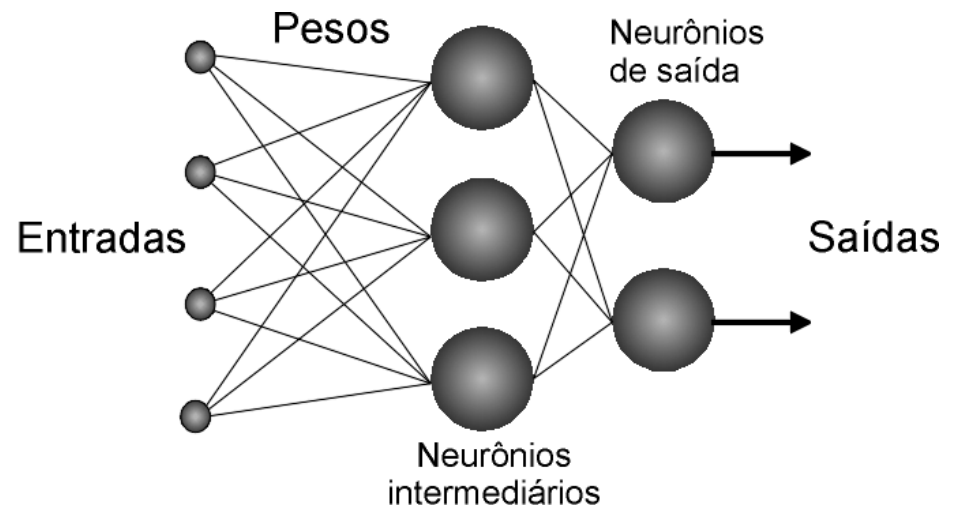

Dentro desse contexto, o principal objetivo deste trabalho é obter uma única RNA para se modelar a cinética da fermentação alcóolica do hidrolisado de bagaço de cana-de-açúcar concentrado com melaço, em diferentes temperaturas. Para isso, foram testadas diversas estruturas com uma camada intermediária a fim de se obter a estrutura que melhor descrevesse tal processo.

\section{MATERIAIS E MÉTODOS}

\subsection{Obtenção dos Dados Experimentais}

Os dados experimentais utilizados neste trabalho foram obtidos do trabalho de Andrade (2012), o qual utilizou o hidrolisado do bagaço da cana-de-açúcar concentrado com melaço como matéria-prima para a fermentação a etanol, ou seja, o processo integra etanol de primeira e segunda geração. O microrganismo utilizado em todos os ensaios foi a Saccharomyces cerevisiae. A Tabela 1 apresenta as temperaturas dos experimentos realizados e o tempo de fermentação de cada um.

Tabela 1 - Temperaturas e tempo de fermentação de cada experimento

\begin{tabular}{cc}
\hline Temperatura $\left({ }^{\circ} \mathrm{C}\right)$ & Tempo de fermentação $(\mathrm{h})$ \\
\hline 30,0 & 35,31 \\
32,0 & 21,10 \\
34,0 & 30,45 \\
36,0 & 27,08 \\
38,0 & 26,60 \\
\hline
\end{tabular}




\subsection{Tratamento dos Dados de Entrada e Saída}

Para o treinamento da rede foi necessário gerar uma maior quantidade de pontos experimentais, pois o número de coletas nos experimentos de Andrade (2012) é limitado para se treinar uma RNA. Para isso, foi utilizado o programa Table Curve 2D para ajustar curvas sigmoidais aos dados de concentrações de células, substrato e etanol. Foram gerados 100 pontos para cada experimento, que é um valor considerado aceitável no treinamento e na validação do modelo. Os dados de entrada e saída utilizados não foram normalizados e alimentados com seus respectivos valores originais.

\subsection{Simulações}

A utilização de uma RNA depende do aprendizado da rede com relação ao problema. A aprendizagem ocorre devido à mudanças nos pesos sinápticos, por emprego de um algoritmo de otimização que tenta minimizar a função objetivo. Neste trabalho, para se determinar os pesos sinápticos da rede, a função objetivo, dada pela Equação 1 foi minimizada.

$$
F_{o b j}=\sum_{i=1}^{m} \frac{\left(y-y^{\prime}\right)^{2}}{m}
$$

em que: $y$ é o valor estimado pela rede, $y$ 'é o valor real fornecido à rede e $m$ é o número de dados experimentais fornecidos a rede.

A estrutura geral de rede selecionada foi: uma camada oculta, variando-se o número de neurônios na camada intermediária, sendo eles 3, 5, 7 e 10. Todas as camadas tinham como função de transferência a tangente hiperbólica. Os parâmetros escolhidos como variáveis de entrada foram: as concentrações de substrato, de células e de etanol no tempo t e t-1, e as temperaturas de cada experimento. Como variável de saída foram escolhidas as concentrações de substrato, células e etanol no tempo $\mathrm{t}+1$.

Essa estratégia foi adotada, pois as RNAs da forma como foram concebidas, funcionam para tratar dados em equilíbrio. Dessa forma, torna-se necessário embutir algum parâmetro temporal no ajuste do modelo. Na etapa de treinamento das RNAs, os dados foram divididos entre treino, validação e teste para cada estrutura, sendo que a porcentagem para cada um foi $70 \%, 15 \%$ e $15 \%$, respectivamente. $\mathrm{O}$ método de otimização escolhido foi o Resilient Backpropagation (Riedmiller e Braun, 1992). Todas as simulações foram realizadas utilizando-se o software MatLab® R2015a 64 bits.

Em seguida, utilizando-se a RNA que apresentou os melhores resultados no treinamento, foi realizada a etapa de simulação. Tal etapa consistiu em utilizar a RNA treinada para gerar os valores de saída a $\mathrm{T}=36^{\circ} \mathrm{C}$ (não apresentada no treinamento - Tabela 2), utilizando-se as condições iniciais do experimento realizado por Andrade (2012). Por fim, os resultados gerados pela RNA foram comparados com os dados experimentais coletados nessa temperatura. Na Tabela 2 são apresentadas a etapa correspondente de cada temperatura e as faixas de valores dos dados utilizados para o treinamento da RNAs e na posterior simulação. 


\section{RESULTADOS E DISCUSSÃO}

Os dados experimentais obtidos foram modelados utilizando diferentes estruturas de RNAs. $\mathrm{Na}$ Tabela 3 são apresentados os valores de função objetivo e coeficiente de correlação, $r^{2}$ para cada uma das estruturas testadas para a modelagem.

Analisando a Tabela 3, pode-se observar que todas as redes obtiveram um alto valor de $r^{2}$. Por esse motivo, tornou-se necessário se avaliar outro parâmetro para determinar a melhor estrutura. Assim, analisando-se a função objetivo, a rede com 10 neurônios na camada intermediária foi a considerada a mais satisfatória, já que ela apresentou o menor valor. Portanto, a estrutura 7-10-3 foi a escolhida para se realizar a simulação.

Tabela 2 - Parâmetros de entrada da rede para o treinamento e simulação

\begin{tabular}{ccccc}
\hline Etapa & Temperatura $\left({ }^{\circ} \mathrm{C}\right)$ & Células $(\mathrm{g} / \mathrm{L})$ & Substrato $(\mathrm{g} / \mathrm{L})$ & Etanol $(\mathrm{g} / \mathrm{L})$ \\
\hline Treinamento & 30 & $2,63-6,63$ & $145,895-0$ & $6,959-72,358$ \\
Treinamento & 32 & $2,72-6,50$ & $144,522-7,290$ & $0,669-59,773$ \\
Treinamento & 34 & $2,60-6,43$ & $149,473-0$ & $2,874-73,156$ \\
Simulação & 36 & $3,12-6,70$ & $147,817-0$ & $2,872-62,096$ \\
Treinamento & 38 & $2,40-6,07$ & $148,285-0$ & $1,133-71,762$ \\
\hline
\end{tabular}

Tabela 3 - Valores de função objetivo e $r^{2}$ para as diferentes estruturas das redes

\begin{tabular}{cccc}
\hline Estrutura & Função objetivo & $r^{2}$ treinamento & $r^{2}$ validação \\
\hline $7-3-3$ & 8,40 & 0,999 & 0,999 \\
$7-5-3$ & 0,92 & 0,999 & 0,999 \\
$7-7-3$ & 0,31 & 0,999 & 0,999 \\
$7-10-3$ & 0,07 & 0,999 & 0,999 \\
\hline
\end{tabular}

A simulação consiste em utilizar uma RNA treinada, mas que utiliza valores das variáveis de entrada que não foram previamente apresentados na etapa de treinamento. É importante salientar que os valores das variáveis utilizadas precisam estar dentro da faixa daqueles apresentados no treinamento. É sabido que as RNAs não possuem capacidade de extrapolação.

As Figuras 2 e 3 apresentam os gráficos que foram construídos a partir dos valores experimentais, do treinamento e da simulação para a rede escolhida. Na Figura 3, símbolos sem preenchimento representam os valores calculados pela RNA e os preenchidos, os experimentais obtidos no experimento a $36^{\circ} \mathrm{C}$.

Analisando-se a Figura 2, é possível observar que o treinamento foi bastante efetivo, já que a forma do gráfico é praticamente uma reta a $45^{\circ}$, o que indica que os dados gerados pela RNA e os experimentais são quase equivalentes, para todas as variáveis de saída. 
Ainda, ao se observar a Figura 3, pode-se afirmar que a RNA foi capaz de simular satisfatoriamente o processo de fermentação a $36^{\circ} \mathrm{C}$, já que os valores simulados seguiram o comportamento dos dados experimentais.

A Figura 4 apresenta os perfis dos dados de concentração de substrato, células e etanol da simulação para a rede escolhida em comparação com os dados do treinamento para as demais temperaturas. Os perfis apresentados reforçam a capacidade da RNA de prever um perfil totalmente diferente daqueles que foram apresentados na etapa de treinamento.

Figura 2 - Valores preditos versus valores experimentais da etapa de treinamento

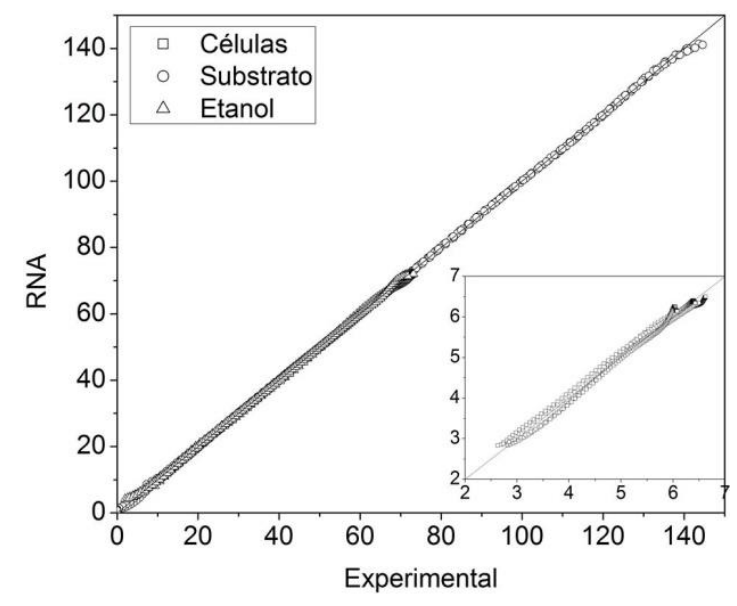

Figura 3 - Perfil da cinética de fermentação experimental e simulado pela RNA a $\mathrm{T}=36^{\circ} \mathrm{C}$.

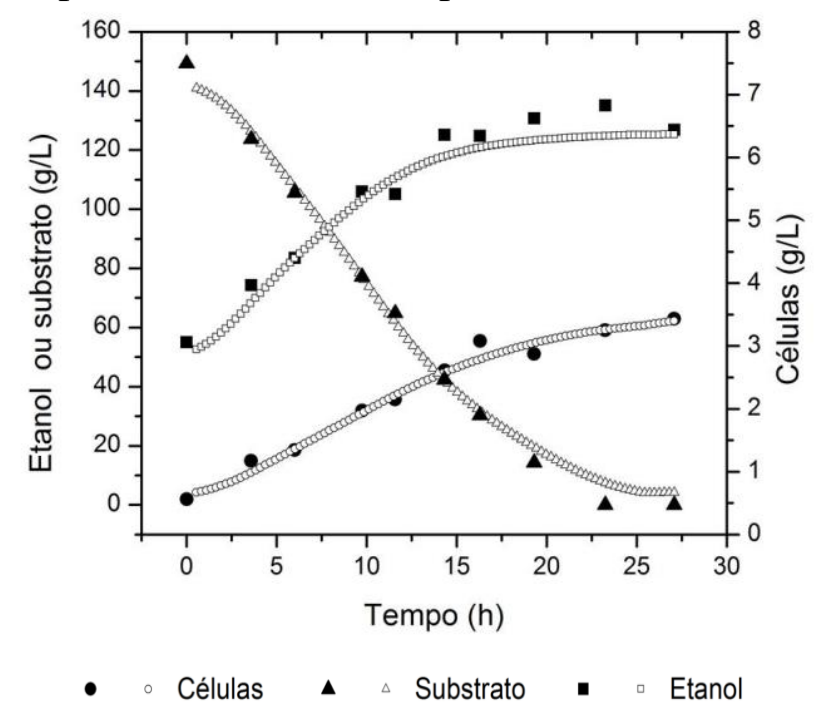

Figura 4 - Comparação entre os perfis gerados pela simulação a $36^{\circ} \mathrm{C}$ e o treinamento da RNA 7-10-3.
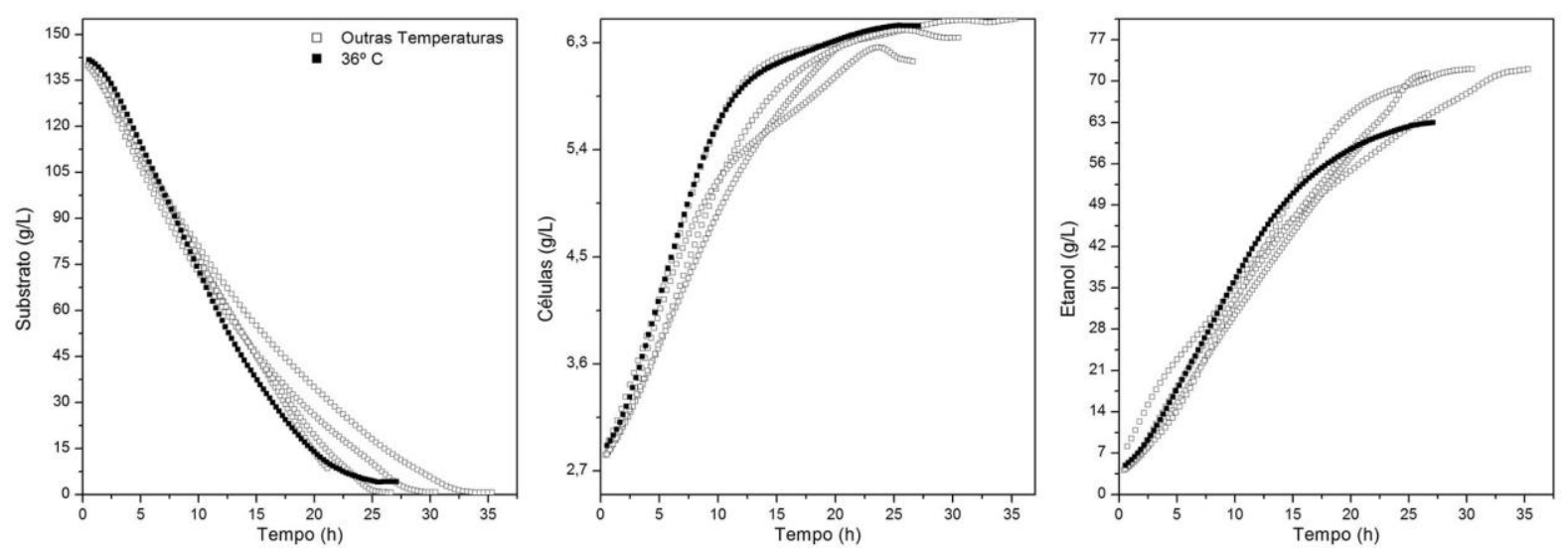

Em Andrade (2012), a modelagem matemática desses dados, utilizando um modelo fenomenológico, resultou em desvios padrões residuais de até 19,6\%, aparentemente muito acima dos obtidos neste trabalho. Além disso, aqui foi possível predizer os dados a $36^{\circ} \mathrm{C}$ sem a 
necessidade de se utilizar a variável concentração de ácido acético, sendo que essa variável dificultava o ajuste do modelo fenomenológico. Em Andrade (2012), devido à necessidade da adição de um termo de inibição por ácido acético, o número de parâmetros consequentemente aumentava, tornando o ajuste do modelo mais complexo e trabalhoso. Vale salientar que não é possível calcular desvios padrões residuais neste trabalho, pois a RNA fornece informações a intervalos de tempo fixos, que nem sempre coincidem com os pontos experimentais coletados.

Este trabalho mostrou que, ao se considerar um modelo neural, apenas os valores de Substrato, Produto e Células foram suficientes para a descrição da cinética de fermentação para todas as temperaturas. Soma-se a isso, o fato de a RNA ser uma equação direta, ou seja, uma vez treinada não são necessários métodos de integração para sua resolução, tornando muito mais simples e computacionalmente eficiente a sua implementação no ambiente industrial.

\section{CONCLUSÃO}

Neste trabalho, foram empregadas RNAs para modelar a cinética da fermentação alcóolica do hidrolisado de bagaço de cana-de-açúcar concentrado com melaço, em diferentes temperaturas $\left(30^{\circ} \mathrm{C}\right.$ a $\left.38^{\circ} \mathrm{C}\right)$. As variáveis de interesse foram as concentrações de substrato, células e etanol no tempo $t+1$. Os resultados mostraram que a rede com 10 neurônios na camada intermediária se mostrou satisfatória tanto nas etapas de treinamento, quanto para simular a cinética de uma temperatura não apresentada previamente. Este trabalho confirmou que as RNAs são uma alternativa viável para essa tarefa, pois frente aos modelos fenomenológicos, os quais ainda não se tem total domínio sobre a cinética de crescimento da Saccharomyces cerevisiae em meios de cultivo contendo ácido acético, furfural e hidroximetilfurfural, foi possível modelar satisfatoriamente o processo.

\section{AGRADECIMENTOS}

Agradecemos ao CNPq pelo suporte financeiro ao desenvolvimento desse trabalho.

\section{REFERÊNCIAS}

ANDRADE, R.R., Modelagem cinética do processo de produção de etanol a partir de Hidrolisado enzimático de bagaço de cana-de-açúcar concentrado com melaço considerando reciclo de células. Tese (Doutorado em Engenharia Química). Universidade Estadual de Campinas, 2012.

BRAGA, A. P.; CARVALHO, A. P. L.; LUDERMIR, T. B. Redes neurais artificiais: teoria e aplicações. Rio de Janeiro: LTC, 2000.

FONSECA, A.P.; OLIVEIRA, J.V.; LIMA, E.L. Neural Networks for Predicting Mass Transfer Parameters in Supercritical Extraction. Braz. J. Chem. Eng., v. 17, n. 4-7, p. 517-524 São Paulo, 2000.

RIEDMILLER, M.; BRAUN, H. Rprop - A Fast Adaptive Learning Algorithm. Proceedings of the International Symposium on Computer and Information Science VII, 1992. 